\title{
From Alice to everywhere, with love
}

\author{
A leap into the unknown.
}

\section{Chaz Brenchley}

The problem was that someone had to go. Slowly, irrevocably, actually go.

The aliens, when they came, were ... properly exotic. Difficult to see, difficult to understand. Their ship pulsed to indetectable rhythms; chilly computers sweated to find a pattern they could analyse.

The aliens brought a machine, the great phase-transmitter that stands on Salisbury Plain. With painful caution, they explained its function. They demonstrated; one by one, they entered the machine and were gone. Transmitted, relocated, somewhere else. Other aliens would come by return; there would be two-way traffic. The speed of light is the speed of information and light is an idler, but they would come.

It would not work for humans, yet. The phase-transmitter needed a template to work from. Uncountable numbers of these machines were spread across the Galaxy, and each of them would have to examine a living human before it could accept one in transmission.

Before humankind could take even a single phase-jump to the nearest station, someone had to go the slow way, in the ship.

Alice Temple had spent her life immersed in the science of language: first as an academic, then - since the aliens came - as a practitioner. At the same time, she had raised a husband and two children from idiocy to independence. She had achieved respect within her profession, renown outside it: and still she was unsatisfied.

Not bitter, not malcontented; shortchanged, rather. She had done the best and the most that was available, and it wasn't enough. It had been too easy. Success ought not to be this cheap.

It was she who found a way to communicate with the aliens; of course, she was on the panel that decided who should leave with them. She sat through days of interviews with bright, healthy, noble young volunteers - and in the end, she said no.

"No," she said. "It has to be me."

It had needed her to make the aliens comprehensible here on Earth; it would need her again, to make humans comprehensible elsewhere.

When the others were done arguing the point, they argued outside it: her age, her responsibilities, her entitlements. She might make the journey in cold-sleep, but it would still be 30 years at sub-light

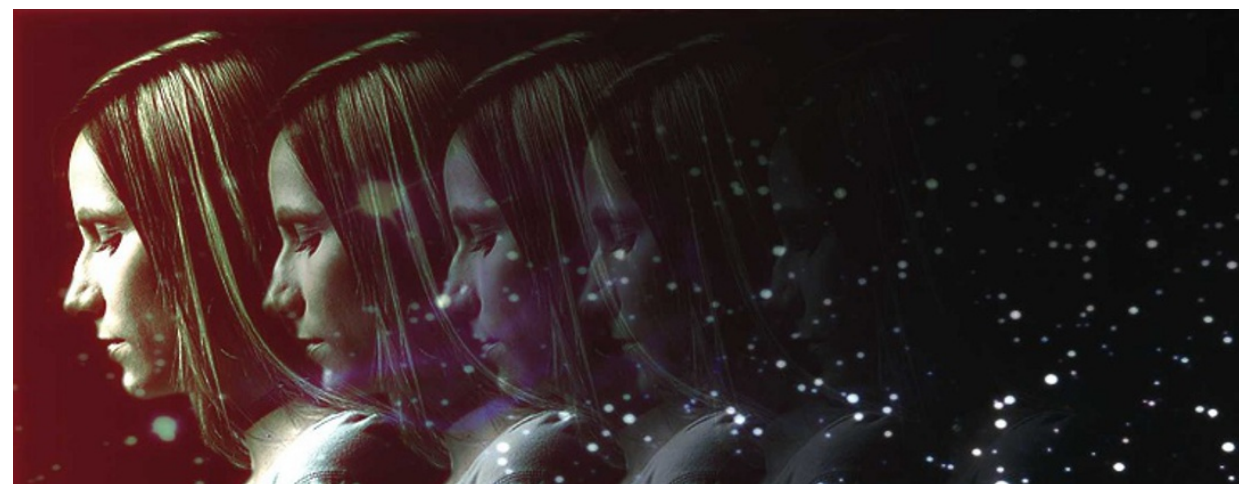

speeds. She could come back through the machine, but even so: her parents would be dead, her unborn grandchildren would be having children of their own, she'd be out of her proper time, adrift. Better to dwell gracefully in her achievements, and leave adventure to the young ...

It wasn't about grace, she said, nor yet adventure. It was necessary: to the project, to the planet and also to her. She needed to do this thing.

She was right, and finally they confessed it. When the alien ship left, she was the one in the cryo-tank.

She remembered being the one who went into the tank. Now she was the one coming out of it, with the deep knowledge in her bones of time and distance passed. She was still herself, this was still her body, but something had shifted between them.

This place, this time was not her own or anything like it. Just a terminal, a switching-place, a depot on a cold moon: there was a phase-transmitter constantly busy and a spaceport too, just as busy. Only living matter could go through the machine. Everything else must be carried, by oldschool traders prepared to spend lifetimes in cold-sleep between brief spells ashore.

They took her to the machine, and it ... engulfed her. She felt its slow and intimate examination like a reverse of the cryo-tank, endless awareness of going nowhere.

Once it had what it needed, it gave her back to herself; they said she could go home. Immediately, if she cared to: be the first human to pass this way, through the phase-transmitter to Earth.

"And then what?" she asked.

Why, then humans could transport here, at light-speed at last; and the young, the vigorous, the bold could go onward in ships to open up new routes to other planets, other vistas ...

"What for me?" she said. "If I go home?" They couldn't answer that, but she could.
A little brief celebrity and a resumed lifetime of disappointment, of feeling that there should have been something more.

The alternative, of course, was to go on. Someone else could carry the message, that this portal was open to humans now. Before anyone arrived she could be well on her way to the next, beating a trail forwards.

But oh, this was a slow way to the stars, eked out, one body, one gateway at a time...

She mused, she argued with herself; at last, she asked more questions.

Yes, they said, the portal could be reconfigured, looped around to send its message to itself; but ..

Yes, they said, the data stream could be divided, to make two copies of the same individual; but ...

But, they said, catching on at last, the process would be lossy. Neither one of her would be what she was now. Not so sharp, not so vibrant. Less Alice.

Yes, they said, the iterations would still be perfectly good templates for the machines.

Yes, they said, if the beam could be split once, it could be split a dozen times.

But ... carried a passenger. Like a starburst, Alice sent herself to a dozen other portals; and then again, a dozen each from those. And so on and on, fading and multiplying, slicing herself thinner and thinner until there was not enough Alice left to sustain a living body. Five billion living bodies.

It wasn't really humankind that flung outward to the stars. It was Alice. Chaz Brenchley has been a professional writer since he was 18 , working mostly in crime, horror, fantasy and science fiction. He claims to live down the dirty end of genre fiction. In fact, he lives in Newcastle upon Tyne.
The next dozen cargo-ships to leave each 